\title{
Staff Culture of Starbucks Part-time College Students
}

\author{
Qitian Mao ${ }^{1 *}$, Muzi Liu ${ }^{2}$ Kejun $\mathrm{Ye}^{3}$, Ken Qin ${ }^{4}$ \\ ${ }^{I}$ Shanghai World Foreign Language Academy, Shanghai, Shanghai 201100,CChina, qitianmao_2019@stu.swfla.org \\ ${ }^{2}$ Nanjing Foreign Language School, Nanjing, Jiangsu 210008, China, liu.muzi@outlook.com \\ ${ }^{3}$ North Cross School, Shanghai, Shanghai 200940, China, shellyye11@outlook.com \\ ${ }^{4}$ School of Obridge Academy, Shenzhen, Guangdong 518026, China, 2652525065@qq.com \\ *Corresponding author. Email: qitianmao_2019@stu.swfla.org
}

\begin{abstract}
This article, which mainly discusses the staff culture of part-time college students at Starbucks, aims to offer insights into building satisfying staff culture and excellent working environment. The paper begins with a comprehensive description of the working site of part-time workers where we conducted out observation, applying the research method of ethnography into the study by making a general review of ethnographic observation and interview principles. The paper summarizes data from interviews with the targeted community and related individuals to elaborate on how socialization at working site enables part-time staff to better enjoy the working routine and results in more positive service attitudes towards customers. The passage also includes reflections upon the observation how the positionality of observers influence the research process.
\end{abstract}

Keywords: Part-time job, Starbucks, College students, Ethnography

\section{INTRODUCTION}

\subsection{Background}

Given the stark shadow cast by the dark green sunshades beside the coffee shop and the occupied armchairs under the protection of the canvas, one could easily conclude that the sweltering summer has just reached the city when students are beginning to enjoy the holidays. Those longing for caffeine would stroll inside, when the artificial cold breeze from the air conditioner could immediately be felt, creating an unnatural contrast, but also brings a sense of security inherent in modern technology. The store's interior is decorated in a subdued, vintage style, with an overall woody feel that complements the unique dark accent green color that neatly corresponds with the sunshades, constructing a sense of subtle vibrancy of the trees. The stereo plays a variety of absolute music with a sense of relaxation and calmness, and the piano and trumpet sounded in succession. Except for the music, there is only the sound of the keyboard and whispering, adding to the unique soothing atmosphere contributed by the slightly narcotic aroma of coffee overflowing all around.

This is a site of Starbucks lying in one of the busy blocks in Shanghai, China. Located in the outskirts of a newly-established shopping mall, the customer flow isn't too sparse. As a classic socializing site for youngsters, the staff of Starbucks, unsurprisingly affected by the type of consumers, were occupied by young adults. Young people do a range of jobs such as greeting customers, making coffee, etc. During the busier hours there are four to five staff members. It's not that they don't talk to each other; on the contrary, you can often hear them chatting softly in this quiet atmosphere, mostly seeming to be unrelated to work.

Among them was a man about his twenties, with curled permed hair and round frame glasses, one of our interviewees(hereinafter referred to as $\mathbf{S}$ ). We discovered that he worked here part-time during the holidays while studying in one of the universities in Shanghai. When being asked about the reasons for his choice to work here, $\mathrm{S}$ mentioned how he researched possible part-time locations, and finally decided upon Starbucks after knowing the coffee giant has retained the title of "Best Employer" in the lists given by Aon Hewitt five years in a row. He believed that the corporate culture of Starbucks could provide him with a rewarding part-time experience, working and socializing with his contemporaries and customers as well. It turned out, according to $\mathrm{S}$, just as he had imagined, only that he got more than what he came for. 
It therefore became intriguing. How did clerks working in Starbucks, especially college students with little working experiences, enjoy the aura of the brand, whether from fellow co-workers, from the interactions rendered by Starbucks' features, or else?

Therefore, in the work, we prepared our research and observations, and wrote the paper as follows.

\subsection{Research Question}

In this work, our group conducted our research in the particular setting of the Starbucks at 8th Minhong Rd. L137, Shanghai, China. After our initial brief observation and interviews, we have found out that many of the staff members are college students and work here as part-time employees. According to part of our preliminary findings, the relatively accommodating environment of the Starbucks makes it a suitable setting for socialization. The resulting communication and interaction between staff members attracted us to explore into the cultural environment of these staff members that comes from the interactions rendered by Starbucks' features. We investigated mainly three aspects, each one deeper and more specific as follows: how part-time staff enjoy the staff culture of Starbucks; how they carry out their daily work; and how they interact with fellow co-workers and the customers. We focused on the way staff members socialize during work or break, aiming to portray this specially friendly working environment for college students working as part-time employees.

\section{METHODOLOGY}

\subsection{Review on Ethnographic Research}

In our research on the culture of the staff community in Starbucks, the research method of ethnography is involved. Ethnography is a qualitative research method on knowing the world, featuring the perspective of social relations of an unfamiliar culture. It is the study about groups of people as they go about their everyday lives. It involves hands-on, on-the-scene study of social behavior of participants in a given situation, requiring full sensory experience on site and participant observation.

To better understand the method of ethnography and apply such research methods into practice, we've read through several related materials, from which we gained insight into our research framework. In Ethnographic Eyes which elaborated on how teachers conduct observation in a classroom and get equipped with such knowledge to better know about and teach students in this setting, Carolyn Frank described the term 'culture' as 'something those people 'have',... It's also what happens to you when encountering differences, become aware of something in yourself, and work to figure out why the differences appear.' (p.3) [1]. From such interpretation of culture, we feel inspired to add our thoughts, or observant comments, into our field notes, which not only serve as a process of analyzing the logic behind what we see, but also an opportunity to reflect upon ourselves, on how we are subtly influenced by the setting we are in and how we, as cultural outsiders, view the specific community and its culture within the observation. Such type of mindset is constantly suggested in ethnographic works, as Howard Becker wrote in How I Learned What a Crock Was[2], in working with college medical students, Becker explored the unique culture of the medical student community by learning about the meaning of a commonly used term 'crock', from which Becker learned that medical students required practical experience, out-of-textbook knowledge, and the time saved for such learning. The term represented an 'insider' insight into the aura of this student community, and for Becker, it was an access point of a deep dive into the students' psychology.

Apart from participant observation, to further understand a culture from a more comprehensive and authentic perspective, talking directly to the cultural insiders is an efficient approach of exploration. Thus, interviews, which could provide an insider point of view, would be a rich source of information. As James Spradley summarized in his study[3], the process of building up rapport with the informants and collaborating on the research through interview could be primarily divided into four stages: apprehension, exploration, cooperation and participation. It described the progress of the interviewer first facing uncertainty and negative feedback on collaboration from informants, gradually getting familiar and trying out new relationships, then building mutual trust and knowing what to expect from each other, and finally cooperating and receiving information analyzed by informants from them. Spradley suggested that ways of cultivating rapport during an interview include repeating informants' explanations, restating what informants have said, and asking for the 'use' instead of 'meaning'. On that last step, Spradley further elaborated that asking about why informants do something would sound judgemental or even invasive, which could be easily misunderstood; however, when asking how or in what way people do things, informants would be more likely to put down defense and become willing to share key information. In addition, Spradley's suggestion on making descriptive questions beginning with 'could you talk about...?' or 'I would like to hear more about...' also inspired us on how to carry out interviews with the informants in real settings. In real setting observations, the interview part would be of great significance to us, because the employee community has certain working norms and ethics and unique staff culture, which could be mostly conveyed to us through interviews.

In the process of participant observation and interviews, the reflection on the observers ourselves would also be essential. According to our professor 
Marjorie Orellana[4], who is also the instructor of ours on this proposal, the critical terms of 'reflectivity' and 'reflexivity' could provide us with two opposite and complementary perspectives on the research object. The former refers to 'reflecting light onto others', while the latter means exploring outward and then 'settling back to ourselves'. The terms reveal both an insider and an outsider point of view, emphasizing on the significance of experiencing the journey ourselves and immersing into a specific unfamiliar culture of a setting, which is the technique we would apply in the reflection of our positionality in our following proposal.

\subsection{Interview}

To give a more comprehensive description, we prefer to write down field notes as detailed as possible both before and during the interview. By applying contextual inquiry, we would also observe and focus on interviewees' feelings through their facial expressions, tones, and illustration of the experience in Starbucks to bring vital details of their behaviors to light.

To fully present the picture of college students taking part time jobs in Starbucks, we would not only give interviews to our main- observing workers in the Starbucks, but also the various groups of people. We sort people into four types of group-customers who come only buying take-away coffee or customers sitting there to study or to finish work, other staff who work in Starbucks, and supervisors or managers in Starbucks. We separated our four team members so each person is able to interview each group of people. By interviewing four groups of people and at least two for each group, we can recognize the disconfirmation of the information.

Before taking the interview, we would make sure the main interviewees are qualified to the condition- college students and part time working through our asking and observing. We would introduce the interviewees with the background of Ethnography and tell them the research question that we are working on. After receiving their permission for the interviews, we would also ask them to introduce their background briefly(Including age, school, grade).

Sometimes, people do not give interviewers the "truth". What I state "truth" here does not simply mean that people would lie intentionally. As professor Marjorie Orellana stated in Ethnography class, the opposite of the "truth" is not always "lie". Part of the reason for interviewees' not stating the "truth" might be that they do not want the essential information to be divulged so they conceal part of the information. On the one hand, people might be unable to catch their actual feelings and thoughts without deep consideration. On the other hand, interviewees' opinions may also be influenced by their current emotions.
At this point, we, as interviewers, would chat with the interviewees firstly to shorten the distance between us instead of starting straight with the strict formal interviews. Certainly, we would give interviewees the commitments of secrecy toward their essential information and ask them to not express their sensitive information.We would also provide interviewees with enough space and time to consider or reconsider their answers. If possible, we would let them "show" us the things rather than just "tell" us. Instead of generalizing the answer, we would encourage interviewees to give detailed answers.

Whenever interviewees are feeling uncomfortable or uncertain of their answers, they are free to skip the question or cease the interviews. After the interview, we would thank them for their participation.

\subsection{Positionality}

\subsubsection{Interviewing part-time college students (Target Interviewee): Alex Mao}

Part-time college students working as Starbucks clerks are the main targets of our interviews and observations. Therefore, we would spend much time interviewing different individuals so as to triangulate our assumptions and "hunches." As high school students(rising seniors), we would seem as peers and contemporaries by our interviewees. This would help a lot when we are pure strangers with them as we want to engage in natural conversations instead of formal interviews and dialogues, so as to obtain the most information from our interactions. On the other hand, them being staff members and needing to work might lead to compressed interviewing length, which makes additional appointments seem necessary.

\subsubsection{Interviewing customers: Barbara}

From an outsider's point of view, I'm a high schooler, who is part of the most frequently seen community appearing in cafes such as Starbucks. This harmless figure would allow me to talk to people without them worrying about their privacy being invaded. Also, when interviewing informants, I would pay exclusive attention to my manners, my tones and ways of speaking, aiming to make the conversations natural and pleasant for my informants. Such features bear great significance when I carry out the interviews with customers in the cafe, for they are mostly random customers and could have their own business going on, probably not preferring to be disturbed too much. In addition, the main consumers in this cafe are of younger ages, which would be close to that of mine, granting me a higher possibility of starting a conversation with them, for most people would feel more comfortable talking to people close to their ages. 


\subsubsection{Interviewing other staffs: Shelly Ye}

I position myself as a high school student who is targeting ethnographic research in college students taking a part- time job as soon as I walk into that Starbucks. But I also position myself as a customer who takes buying drinking as an exchange from getting the chance to interview other staff. From my interviewees- other stuffs' view, I'm one of the customers who is interested in their current life situation. We are close in age so staff tend to not hold back and act prudently. To get more genuine and authentic answers from the interviewees, I try to shorten the distance between me and my interviewees' positions through amicable greeting to initial the chat and eased tone during the interviews. As being both an interviewer and outsider, I would try to not let myself become a barrier of interviewees' thoughts exploring. Instead of giving out leading questions, I try to be more open minded and leave my interviewees space and time to think, reflect and reminisce.

\subsubsection{Interviewing supervisors: Ken Qin}

As a student observer and reporter, I should use some different skills which can make the interviewee feel comfortable and relaxed. In my opinion, I can definitely get a satisfying result as soon as I put myself in the right interviewing position. Only good questions can lead to compelling information. The interviewees are unwilling to discuss profound matters with unfamiliar or stupid people, or to utter repartee that could be used as direct speech. A connoisseur will know if there is one. When a reporter opens his mouth, the interviewer can tell how well you know him or her and how well you know his or her work. Reporters speak strange words that the supervisor won't use in daily working life, it is difficult to obtain the identification of the interviewees, it is not deep talk. This requires the reporter before the formal interview, should be through a variety of channels to the local economic and social development, the interviewee individual and other relevant interview content to understand. Design some important questions around the theme in advance according to what you know and what you need to write. Write down a list of questions and put them in a logical order so you don't forget them during the interview. Important interview at the beginning, might as well and interviewed relaxed A few words, make interviewed relaxed mood, like chat like interview, more can stimulate interviewed to talk Ahope and impulse. In this way, I aim to get more sincere words about how Starbucks works through the efforts of all full time and part time workers from the supervisor, because that will be one of the most significant original resources in this ethnography research proposal.

\section{FINDINGS}

After several observations and interviews with one of the college students that work part-time at the Starbucks at 8th Minhong Rd. L137, we discovered some core corporate culture and values of Starbucks that they participated in and enjoyed. The following information is obtained from conversation with employee $\mathrm{S}$ (mentioned earlier in the introduction). $\mathrm{S}$ is a rising sophomore at a local university, and works at Starbucks part-time during the holidays. He said that he personally quite liked the work atmosphere at Starbucks. Unlike other workplaces, people at Starbucks don't call each other "co-workers", but "pals". In addition, there isn't that much of an age gap, so they are closer to each other, and they will go out for dinner and snacks together during the late shift. I asked about his other and earlier internships, he said he had a very brief internship at a law firm, but it was so intense and strict that he did think about becoming a lawyer afterwards, but he thought at this period of time he would like to enjoy the warm and welcoming atmosphere that Starbucks brings.

$S$ also explained how they need to prepare the materials needed to make coffee in the morning for their colleagues who work on the late shift. In his opinion, this feeling of helping each other is one of the core values of Starbucks he feels, and provides him with a sense of security and warmth.

As for the customer aspect, $\mathrm{S}$ said that his favorite activity when has nothing to do during work is to chat with familiar customers. He felt that rather than working and making money, he was more interested in the socializing experience at Starbucks. Being able to communicate more with strangers and acquaintances is one of the things he finds most valuable about this parttime job. He also really enjoys the process of communication and learning about other people's lives, which can more or less bring him some inspiration for his own. He at times keeps track of the drinks that these customers usually order, including an older man who ordered an iced Americano, and a girl who ordered a matcha Frappuccino, etc.

\section{REFLECTION}

During the whole project period, we learned a lot about Ethnographic research methods from different aspects, including the professor, TA and our classmates. Ethnographic research is describing the way people of a race or a group live, valuing who they are and describing how they act, how they interact, how they construct meaning, how they interpret it. The goal is to discover their beliefs, values, perspectives, motivations, etc, and to understand how these beliefs and values develop and change from the perspective of the members of the group. The more important significance of ethnography as an academic text may not lie in the way of ethnography 
investigation and the writing form of investigation results, but in the presentation of the theoretical paradigm guiding ethnography investigation, that is, the theme that the ethnographer wants to express. Ethnographers, therefore, cannot be satisfied with detailed descriptions of the cultural phenomena of their subjects. But also to explore the theme behind the phenomenon. It's not how you say it, it's what you say. Almost every anthropologist has his own ideas to express, the thing we need to do is to find our own way and methods, then use our own language to write our own descriptions. After a lot of field investigations, although a lot has been gained, there will still be a lot of confusion in the research process, which is exactly what needs to be considered and discussed in the future field investigations and ethnography. In summary, ethnographic research is both a product and a process. In the case of a product, it is the product of research, typically a book-length presentation; In terms of process, it is a long-term observation, through which researchers observe people's lives day in and day out or conduct one-on-one interviews with group members, to study the intention of behavior and the interaction of the culture-sharing group. It is a valuable experience for us to be a part of this project.

\section{CONCLUSION}

In a nutshell, from our observations and interviews, we could see that generally part-time college students at Starbucks enjoyed the friendly environment and how every "pal" helps each other out. Additionally, they engage in conversations with colleagues and customers, a trait unique to Starbucks, being a working and socializing site popular enough. Such findings offer insights into building up staff cultures among other corporations, the key to which is allowing space for socialization between staff members, letting them make connections that results in better service attitudes and mentality of working.

\section{REFERENCES}

[1] Frank, C. (1999) An Ethnographic Perspective, Classroom Observations. In: Lois, B. (Eds.), Ethnographic Eyes: A Teacher's Guide to Classroom Observation. Heinemann, a division of Reed Elsevier Inc., Portsmouth. pp.1-14, 82-93

[2] Becker, H.S. (1993) How I learned what a crock was. Journal of Contemporary Ethnography, 22(1), 28-35.

[3] Spradley, J.P. (2016) The Ethnographic Interviews. Waveland Press, Inc., Long Grove

[4] Orellena, M.E.F. (2019) Mindful Ethnography: Heart, Mind, and Activity for Transformative Social Research. Routledge Publishing Company. 